De Araújo Santos, Eriel.

Profesor de la Universidad Federal de Bahia, Departamento de Expressão Gráfica y Tridimensional, Grupo de Investigación en Arte Hibrida.

\title{
EL Humano en potencia: la materialidad como medio de actualizaciones en propuestas artísticas.
}

\author{
TIPO DE TRABAJO \\ Comunicación virtual
}

PALABRAS CLAVE

Arte contemporáneo, humano, materialidade, virtual, real.

KEY WORDS

Contemporary art, human, materiality, virtual, real.

RESUMEN

Vamos a discutir en este artículo acerca de la importancia y el significado de una superfície o uno medio material en las interpretaciones y estrategias artísticas utilizadas hoy en día. Desde el surgimiento y desarrollo, cada vez más operant y eficiente, de los sistemas de producción de imágenes digitales, existen en paralelo una amplia y significativa gama de investigaciones sobre los medios materiales, ya que la actualización se hace por una cierta materialidad. Entonces pienso que las prácticas artísticas están siempre en contacto con un medio material, sea para vistas de imágenes sea para experiencias en los modos de producción y elecciones simbólicas, expresivas, de interpretación o incluso ajustes a los sistemas no-arte.

\section{ABSTRACT}

We discuss the importance and meaning of a surface or material means with regard to interpretations and artistic strategies used nowadays. Since the emergence and development increasingly operative and efficient for digital imaging systems, there are, in parallel, a large and significant range of investigations of material resources, for the update is made by a certain materiality. We note then, that artistic practices are always in contact with a material medium, whether for image views is for experiments in modes of production and symbolic choices, expressive, interpretative or even adjustments to non-art systems.

\section{CONTENIDO}

La dirección dado al conocimiento de lo que nos rodea está redactado en un cuerpo material. Este cuerpo llamado humano al entrar en contacto con otros cuerpos potencializa su estado sensible y sigue en dirección a la posibles decodificaciones. Los artes en general busca transferir este conocimiento a través de las manifestaciones que articula algo elaborado virtualmente, en la mente, y posibilita la actualización en un determinado medio material.

Percibimos que el virtual se hace real al manifestarse en una materia o medio constituido de materia estática o en movimiento. Así, podemos afirmar que no existe conocimiento sin la presencia de la materialidade. La luz, mientras materia, por ejemplo, viene participando de la formación de imágenes de manera directa o indirecta. La visualización de algo, en forma o color, depende de la radiación de fótons que emanam de los materiales constituyentes de esos elementos. Esos mismos fótons también son responsables por la formación de imágenes en superficies sensibles, como en la fotografía. Y lo que decir de la formación, identificación e interpretación de las imágenes formadas en el cuerpo humano? Un cuerpo sensible. A partir de las cuales podemos decir (SANT'ANA, 2001, p.115) “...que el silencio no sea comprendido únicamente con la falta del lenguaje, y sí con la presencia de sonidos que no conseguimos oír". Imágenes reales que contiene signos virtuales. 
Entendiendo el cuerpo como lugar de passajes (SANT'ANA, 2001), podemos pensar en que medida el pasado, el presente y proyecciones futuras son absorbidas en un lugar/cuerpo a la vez. Es así que el humano reúne sus memorias, ideas y percepciones de la vida que lo cerca. Los acontecimientos vividos y registrados en imágenes y textos parecen conectar con el aspecto de la omnipresencia y onipotência entre el hechos y sus consecuencias. De esa manera, la psicanálise, la espiritualidade, la política, la filosofía y el arte son algunas áreas del conocimiento que busca analizar y reconocer existencias sin necesariamente usar la materialidade como referencia de causa y efecto; pero, tales experiencias virtuales son procesados en un cuerpo, el cuerpo humano. Vale resaltar que la experiencia artística se da en un "estado de arte", cuando el Ser, al encontrar el desconocido, se relaciona de manera risomática, en la cual el reconocimiento de las potencias de las imágenes inscritas en materias son interpretadas libremente, una constitución infinita de significados.

Al definamos lo arte como un campo de conocimiento que establece relaciones con el virtual sensible, estamos proponiendo un análisis de los múltiples factores que llevan hombres y mujeres a construir obras que buscan relacionar el visible y material a las condiciones virtuales inherentes al estado de Ser y Estar en el mundo. Aunque eso nos conecte con el misterio o mundo de las ideas y confabulações, resultan de experiencias en un cuerpo. Una matéria.

Al incorporar tales condiciones en una determinada interpretación artística, parece favorable identificar en que medida eso se da mientras el binomio real-virtual, pues creo que el real, mientras una manifestación inapreensível, luego se hace virtual en nosotros, algunas veces accesible cuando reconocido por la conciencia y otras veces arquivadas en nuestro inconsciente. $Y$ para que sea percibido por otros será necesario una determinada materialidade para que se atualize y se haga real para otros, constituyendo un encadenamiento sígnico. En ese desdobramento, el movimiento del signo sigue modificándose o aún estacionando en un símbolo generador de leyes establecidas socialmente. Así, el movimiento del signo sigue modificándose o aún estacionando en un símbolo generador de leyes establecidas socialmente. Pero, los símbolos son capaces de se resignificar en función de otras direcciones interpretativas. Verificamos entonces, que muchos artistas están trabajando, en sus procesos creativos, para dar otros significados a los materiales, imágenes y acontecimientos generados a partir de nuestras experiencias, sea por el contacto directo sea por interpretaciones registradas en imágenes, objetos o textos.

Florence de Mèredieu en su libro "Histoire matérielle et immatérielle de l'art moderne", llama la atención para la "idée de s'incarner" a partir de un color o forma construida por los artistas. Ella destaca, principalmente, las producciones artísticas que envuelven la utilización de los materiales que definieron los artes plásticos, los cuales poseen valores destacados por varios artistas al largo de la Historia. Pero, al referirse al arte del vídeo y arte numérico "puramente imaterial" (2004, p.51), pienso que existe un reducionismo en esta afirmación, pues esas producciones acontecen mediante reacciones entre materiales constituyentes de objetos físicos: circuitos electrónicos, equipamientos digitales y propagación de la luz (luz es materia). La virtualização se encuentra en la materialidade de los elementos constituyentes de esos objetos, a la espera de su actualización. Esta actualización se da por la potencia de esos elementos. Podríamos afirmar que existe potencias en las materias y materiales orgánicos e inorgánicos que están en constante interacción con la potencia del sensible en nuestros cuerpos.

La potencia del sensible, que aquí me refiero, puede ser subdividida en consonancia con su manifestación física o psíquica en nuestro cuerpo. Pensando así, podemos identificar cuestiones de orden social, psíquica y física, atribuidas a una determinada materia. Socialmente percibimos que la potencia de una materia establece conexiones con el sagrado, el poder económico y estatus social, adquiriendo diferentes significados cuando encontrados en tiempos y lugares distinguidos. Al aproximemos de una determinada materia, podemos conectarnos con nuestra memoria y establecer conexiones psíquicas com el vivido o añadir nuevas "informaciones" adquiridas por la experiencia actual, donde el real se hará virtual en nuestro imaginario. Las cuestiones de orden física son primordiales, pues a partir de las sensaciones visuales, táteis, gustativas, olfativas y auditivas que hayamos con los materiales, somos capaces de identificar en el real posibles conexiones con sus potencias.

Cuando un artista encuentra o escoge un medio para hacer su idea real, aún cuando tratándose de una obra conceptual, pues es necesario una materialidade para que ella pueda existir sea un texto, sonido o imagen, él escoge en función de su apariencia y valores reconocidos por el sensible o manifestados en su cultura material. A partir de ese momento inicia una especie de metamorfose, pues lo que vemos apunta para varias direcciones interpretativas. La gana de tocar, arañar, mezclar, destruir o aún hablar sobre una determinada materia nos aproxima de su potencia primera. Sin embargo, al entrar en contacto con esta, descubrimos que se trata de algo más. Existente además de su apariencia visual, pues

Las imágenes imaginadas son antes sublimación de los arquétipos del que reproducciones de la realidad. Y como la sublimación de los arquétipos es el dinamismo más normal del psiquismo, podremos mostrar que las imágenes salen del propio fondo humano... la imagen tiene una doble realidad: una realidad psíquica y una realidad física. Es por la imagen que el ser imaginante y lo ser imaginado están más próximos. (BACHELARD, 2013, p.3)

Sea una imagen construida de pigmentos y óleos, sea una imagen fijada en una superficie sensibilizada por substancias químicas, aún aquellas que son depositadas sobre un papel, o aún participando de una nube de vapor d'agua, necesitamos de esos materiales para hacer real una imagen imaginada. 
Artistas como Bill Viola, Anish Kapoor, Marina Abramović, entre otros parecen exclamar un sublime contemporáneo, en el cual la realidad ultrapasa el cuerpo y alcanza un otro estado de realidad, avanzando en dirección al incompreensível por las leyes de la lógica ordinaria, pero reconhecível por la potencia de las imágenes instauradas en materias y sistemas. Entendiendo los sistemas como reunión de acontecimientos conectados directa o indirectamente al cuerpo humano. La materialidade presente en las obras de esos tres artistas, por ejemplo, posee características que los aproximan mientras por una conexión con el humano, algo esencial para el reconocimiento de sí, en un torbellino cada vez más caótico que se presenta la realidad.

En "Martyrs" Bill Viola elige un tema del cristianismo para conducir su creación. Para taal fin, él reconoce en el contacto del cuerpo humano con materiales simbólicos de nuestra existencia (tierra, aire, fuego y agua) una posibilidad de hacer en imágenes algo que no conseguimos decir a través del verbo. Mediante el lenguaje del vídeo, él creó escenas para las cámaras. En esas escenas podemos testificar interacciones reales y virtuales actuando directamente en la superficie de los cuerpos humanos: una columna de tierra que asciende de un hombre que se arriba, una mujer suspensa por una cuerda y a la vez preza por otra al suelo es azotada por ventos fouertes, un hombre sentado es acometido por una lluvia de labaredas de fuego, y por fin un hombre es içado por una cuerda bajo una torrente de agua que cae del alto. Estas estrechas descripciones relatan parcialmente lo que podemos "ver" en las escenas de los vídeos que componen la obra, pues las calidades visuales encontradas en las velocidades escariadas de las escenas nos conduce a un estado de tranquilidad frente al suplício de un cuerpo en contacto con una determinada materia. En entrevista Viola confiere a las mídias como testigos del sufrimiento de los otros, y dice que "Martyrs" representa la idea de acción, fuerza, perseverancia, resistencia y sacrificio.

La obra de Anish Kapoor, por su parte, comunga con la cultura indígena y el pensamiento budista, de esa manera los materiales son fundamentales para constitución de sus ideas. El color para él se encuentra en la intimidade de la materia, la espera de un contacto, de una vivencia, una revelación. Sobre las materias escogidas:

... en la obra de Kapoor la piedra es el vehículo que transporta de lo divino a lo humano; la piedra, que es algo sólido, tiene la capacidade de convertirse em sublime, lo pétro, em humano. El mineral, que encierra em sí lo desconocido, tiene el poder para producir la transformación de lomaterial em inmaterial y, según la interpretación de los símbolos de Guenon, la piedra está también relacionada con la lyz y con el "núcleo de la inmortalidad", con lo que queda de todo resto humano." (CAMPO, 2006, p.60)

Las reflexiones lanzadas por Eva Fernández Campo sobre la producción artística de Anish Kapoor comprueba la relación de la materialidade con el indecible, una especie de interpretación de la experiencia de nuestro cuerpo con el misterio.

Así como en Kapoor, la obra de Mariana Abramović aproxima cuerpos orgánicos a los materiales inorgánicos. La elección por cristales en muchas de sus presentaciones, Marina invita el participante a experimentar el contacto de su cuerpo con objetos construidos para un fin artístico, com eso instaura un método que discute el relentizar en el mundo y una mirada más atento para el tiempo de aquello que está resguardado en el cuerpo. De esa manera, en "objetos transitorios para uso humano" y "Tierra comunal" ella busca explorar las propiedades energéticas encontrada en los materiales escogidos. De esa manera, en "objetos transitorios para uso humano" y \#8220;Tierra \&comunal" ella busca explorar las propiedades energéticas encontrada en los materiales escogidos. Así, su obra propone al público explorar las fronteras entre el cuerpo y la mente, intermediado por el contacto con la madera y el cristal, en su método usado en "Tierra comunal", por ejemplo. Al participar del método, además de la experiencia con materiales orgánicos e inorgánicos, el tiempo y lo silencio contribuyen para una fruición entre el real, vivido, y el virtual, atualizado en cada cuerpo.

Los procedimientos adoptados por artistas en varios momentos de nuestra Historia establecen "contratos" con los medios materiales. Esos medios, por su parte, corroboram para incontables posibilidades para vivenciar el acontecimiento, como venimos en los ejemplos citados anteriormente. Alguna cosa acontece, y nuestro cuerpo entra en estado de alerta, atención. Como concluye Sartre (2010, p.137) “... la imagen es un tipo de conciencia. La imagen es un acto y no una cosa. Luego, podemos decir que esa toma de conciencia realiza contacto directo con los embates religiosos, políticos, científicos y varios otros comportamientos sociales.

De los modos de hacer arte a los modos de presentar una idea-arte, es en el cuerpo humano que se estabelece y realiza la dinámica real-virtual. Y para que eso pueda acontecer, la materialidade humana entra en contacto directo o indirecto con las calidades de otras materias o materialidades. Con eso, un rayo de luz o la dureza de un metal son capaces de mover células y alcanzar algo que escapa de la clasificación ordinaria existente. Algo que nos parece abstracto, se hace consciente en su existencia y establece nuevos contactos con la realidad.

Hace muy tiempo vengo cuestionando sobre aquello que algunos denominan de arte imaterial, y no conseguía entender la posibilidad de existencia de ese tipo de obra, pues para que una obra exista es necesario la materialidade. Tal vez pudiéramos decir que la imaterialidade se funda en el "estado de arte", y la materialidade es el lugar donde se encuentran los objetos artísticos, artistas y el público en general. El Arte es un estado del Ser, intermediado por una materialidade cualquiera, incluyendo la materialidade de su propio cuerpo.

Al realizar la obra "Alacridade", propongo circunscribir, en un objeto construido por parafina sólida, carbón vegetal y resina sintética, un estado de felicidad y realización. Las asociaciones a un dibujo que no es riscado, una superficie que aparenta profundidad y una imagen abstracta, corroboram para dar sentido al desconocido. Una especie de transferencia de los sentimientos a las composiciones desconocidas hasta entonces. Esta apariencia podrá ser confrontada con el estado de sorpresa, encantamiento y soledad, inherentes a nuestra conexión como sagrado o misterio. Pero, sabemos que este misterio se hace presente en nuestros pensamientos e imaginações. Cuando materializado, su real apariencia no aparece, vemos sólo su representante. 


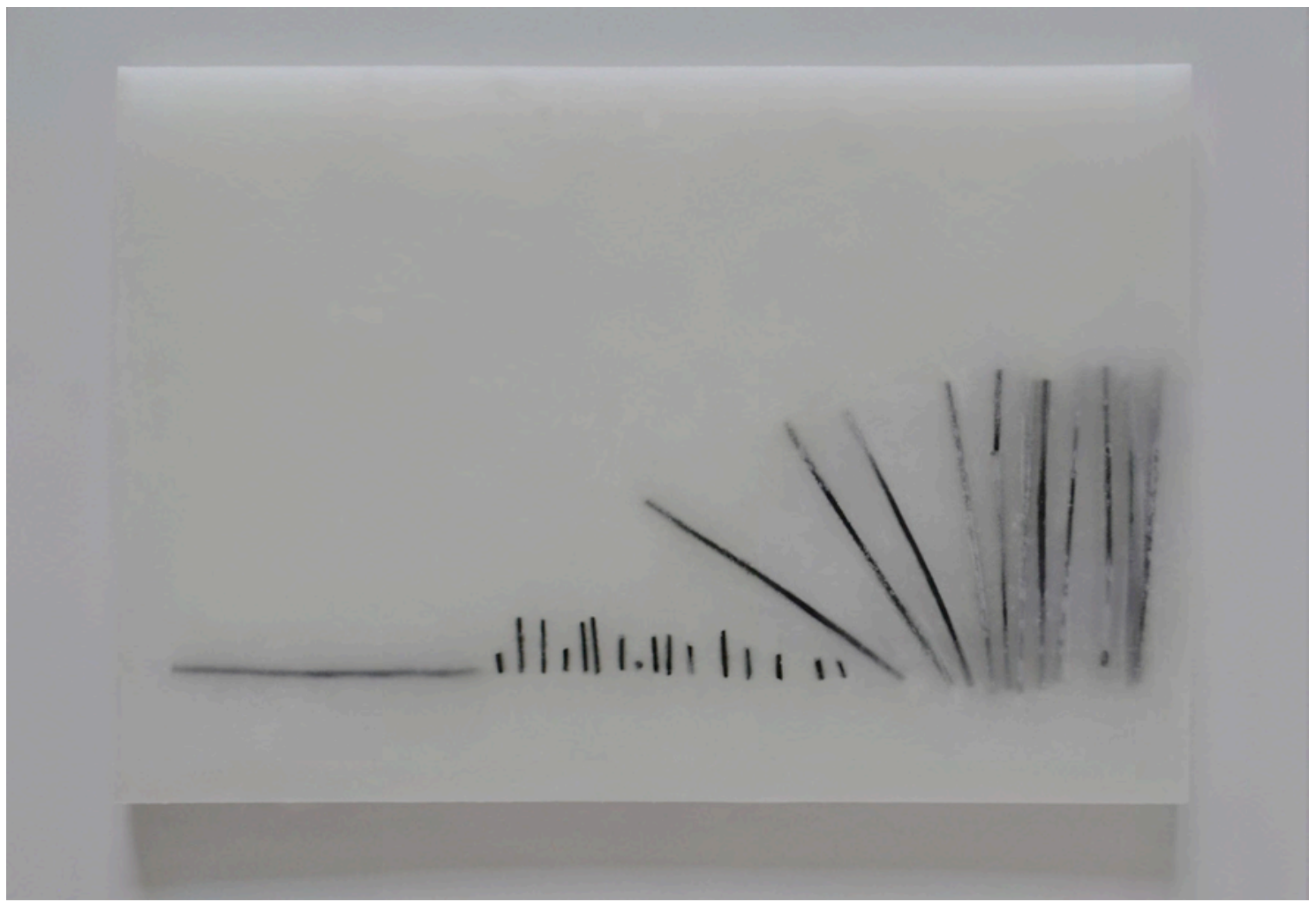

Eriel Araújo. Alacridade. Parafina y carbón vegetal. 32 x 47 x 5 cm. 2015.

Vemos nuestro rostro sólo en imagen, por exemplo, reflejada o fotografiada, una visión intermediada por materiales constituyentes de esas imágenes. Esa apariencia de nuestro rostro en nosotros, nos hace pensar sobre como percibimos las cosas em parte. Y más complejo aún es preguntar sobre la posibilidad de ver aquello que no se materializa mientras calidad física; es necesario invitar actores para encenar una interpretación metafórica, asociativa o reflexiva de aquello que sentimos en nuestro cuerpo. El ritmo gráfico presentado en "Alacridade" busca establecer posibles conexiones con un estado sublimado en una materia.

Aún con el surgimiento de tecnologías para reproducir o aún crear imágenes sintéticas, numéricas, oriundas de los sistemas digitales, las composiciones físicas permanecen ampliando, más allá del determinismo tecnológico sobre el cuerpo y la sensibilidad, el modo de percibir y actuar sobre el real. Un encuentro que activa un determinado dispositivo en nuestra imaginação para el impresentable. Pues, "...para alegrar un impresentable del arte que esté a la medida de un impensable sea integramente pensable, integramente necesario según el pensamento. La lógica de lo irrepresentable sólo se sostiene gracias a uma hipérbole que finalmente la destruye. (RANCIÉRE, 2011, p.143). Al imaginemos lo que puede significar una materia y su semejante en palabras, parece existir un valle, muchas veces peligroso y assustador; pero, ese estado de tensión nos hace agentes capaces de construir interconexiones que conducen al conocimiento dado por la experiencia.

El efecto que una determinada materialidade provoca, parece afirmar que somos sujetados a su existencia y su poder, presente en cualquier periodo. Aún así,

Quiébrese mucho en desaparición o desmaterialización del objeto en el arte contemporáneo, y con eso se pierde de vista su fundamental operación sobre el sujeto: deslocalização y convocatoria - el sujeto es desplazado, delante del objeto, para aparecer como efecto de sujeición. (RIVERA, 2013, p.45)

Al observar incontables maneras de presentar una idea artística, como un tejido o un ambiente de inmersión digital, necesitamos de materiales que respondan a las condiciones poiéticas insertadas en el flujo real-virtual, establecido en un cuerpo material y manifestada en suya anima, conduciendo el humano al reconocimiento de sus potencias y construcción del conocimiento. El contanto con una determinada calidad física, química, físico-química o aún simbólica de un material, califica nuestra percepción y nos conduce a un estado de arte, en el cual podemos descubrir incontables relaciones con nuestro modo de existencia física o social. Con eso, la importancia de la materialidade y la experiencia subjetiva en el arte atribuye una carga de responsabilidad al material escogido para dar "cuerpo" la una realidade artística. 


\section{FUENTES REFERENCIALES.}

BACHELARD, Gaston. A terra e os devaneios da vontade, ensaio sobre a imaginação das forças. São Paulo: Martins Fontes, 2013.

CAMPO, Eva Fernaández del. Anish Kapoor. Donostia: Nerea, 2006.

Didi-Huberman, Georges. Ser crânio. Belo Horizonte: C/Arte, 2009.

MÈREDIEU, Florence. Histoire matérielle et immatérielle de l’art moderne. Paris: Larouse, 2004.

RANCIÉRE, Jacques. El destino de las imágenes. Buenos Aires: Pormeteo, 2011.

RIVERA, Tania. O avesso do imaginário. São Paulo: Cosac Naify, 2013.

SANT'ANA, Denise Bernuzzi de. Corpos de passagem ensaios sobre a subjetividade contemporanea. São Paulo: Estação Liberdade, 2001.

SARTRE. A imaginação. Porto Alegre: L\&PM, 2010. 